\title{
BOND TESTS OF PARTIALLY ENCASED COMPOSITE COLUMNS
}

\author{
Marisa Pecce* and Francesca Ceroni \\ Department of Engineering, University of Sannio \\ Piazza Roma 21, 82100, Benevento, Italy \\ *(Corresponding author: E-mail: pecce@unisannio.it and ceroni@unisannio.it)
}

Received: 31 December 2007; Revised: 22 July 2008; Accepted: 28 July 2008

\begin{abstract}
This paper deals with bond behaviour at the steel-concrete interface of partially encased composite columns. The topic is especially interesting to determine the stress transfer between the two materials at sections where composite structural elements are connected, such as in a beam-column joint, and to ensure a short transfer length to attain the strength of the composite section. The few experimental tests in the technical literature usually concern other types of composite columns. The Authors therefore designed and carried out experimental bond tests to investigate the transfer mechanism and ascertain the reliability of some code provisions (Eurocode 4 [5]; New Italian Code [8]) concerning the design value of bond strength for partially encased columns. A suitable test set-up was designed to measure the shear stresses transferred to the steel profile and the slip between the two materials, allowing compression or tension to be applied to concrete according to monotonic or cyclic load history. The test results give interesting information about the bond stress-slip relationship and bond strength; the cyclic tests highlight the effect of seismic action and indicate considerable degradation of strength and stiffness.
\end{abstract}

Keywords: Composite Columns, Steel-Concrete Structures, Bond Strength

\section{INTRODUCTION}

Steel concrete composite constructions can offer many benefits in structural performance due to technical solutions that allow problems of both RC and steel structures to be solved. However, the design approach still needs suitable procedures and code provisions (Cosenza and Zandonini [1]) since the structural behaviour of steel-concrete composite elements is due to the interaction mechanism between the two materials based on suitable mechanical devices or bond at the interface. In particular the bond between steel profile and concrete is usually completely neglected in the design of beams made of a steel profile and a concrete slab, where the stress transfer is entrusted to mechanical devices (connectors). By contrast, in composite columns the contribution of the bond at the steel-concrete interface can be taken into account in the calculation because the contact surface is wider and the concrete is completely or partially encased in the steel profile, that gives a beneficial confinement effect. A large contact surface usually leads to low bond strengths but allows total interaction of the two materials to be obtained. The composite section can then reach its plastic bending moment; this can happen particularly for sections where the centroids of the concrete and steel section coincide.

The bond mechanism in composite columns is complex and depends on many geometrical and mechanical parameters discussed elsewhere (Virdi and Bowling [2]; Hamdan and Hunaiti [3]; Hunaiti [4]). Behaviour depends on the type of composite column (partially or fully encased, concrete-filled), the shape of the section (rectangular, square, circular), the loading procedure (on concrete, on steel, on both materials), the type of load condition (axial load, bending, tension, cyclic loads), the concrete properties (class, age, shrinkage, creep, temperature). Design values of bond strength are suggested by international codes, such as Eurocode 4 [5] and AISC [6], and Italian codes, such as CNR 10016 [7], and now also by the new technical instructions for constructions in Italy (NTC, DM 14 [8]). 
Clearly, bond capacity is an essential matter in order to ensure suitable stress transfer in the zones where structural elements are connected. Although composite joints can be achieved with various systems, it would be preferable to choose solutions where both materials are loaded in order to transfer the stresses from one element to another more efficiently and attain full composite action. This result can be reached by ensuring sufficient bond capacity to guarantee short transfer lengths or by using mechanical connectors.

The threshold values of bond strength suggested by codes are based on a few experimental results of monotonic tests on concrete-filled composite columns (Khalil [9]; Hunaiti [4]; Kilpatrick and Rangan [10]; Johansson and Gylltoft [11]; Mouli and Khelafi [12]). Some details concerning Khalil's [9]) tests are discussed in section 4 in order to underline the different bond behaviour of concrete in filled and partially encased composite columns. For applications under seismic action, information on the effect of cyclic loads is required to evaluate the severe degradation of strength and stiffness.

In order to study the bond behaviour of partially encased composite columns, tests were designed and carried out at the Laboratory of the University of Sannio at Benevento, Italy. The specimens are made of HEB (double $\mathrm{T}$ wide flange) steel profiles partially encased with concrete, with and without longitudinal and transversal steel rebars. The influence of the interface roughness was tested by spreading the interface with oil in some cases; some tests under cyclic loads were also performed. The test results are presented below; some comparisons with code limits and the results of other researchers on concrete-filled columns are also made.

\section{EXPERIMENTAL PROGRAM}

The tested specimens were made of steel profiles HEB 180 (flange thickness $t_{f}=14 \mathrm{~mm}$, web thickness $\mathrm{t}_{\mathrm{w}}=8.5 \mathrm{~mm}$, width and height of the section $\mathrm{H}=\mathrm{B}=180 \mathrm{~mm}$ ) $630 \mathrm{~mm}$ long with a bond length of $450 \mathrm{~mm}$. The profile HEB 180 (Figure 1a) was chosen in order to have as the maximum dimensions, significant for composite columns in buildings, compatible with the testing machine frame and allow correct positioning of the loading plates and instruments. Bond length was established as 2.5 times the section width.
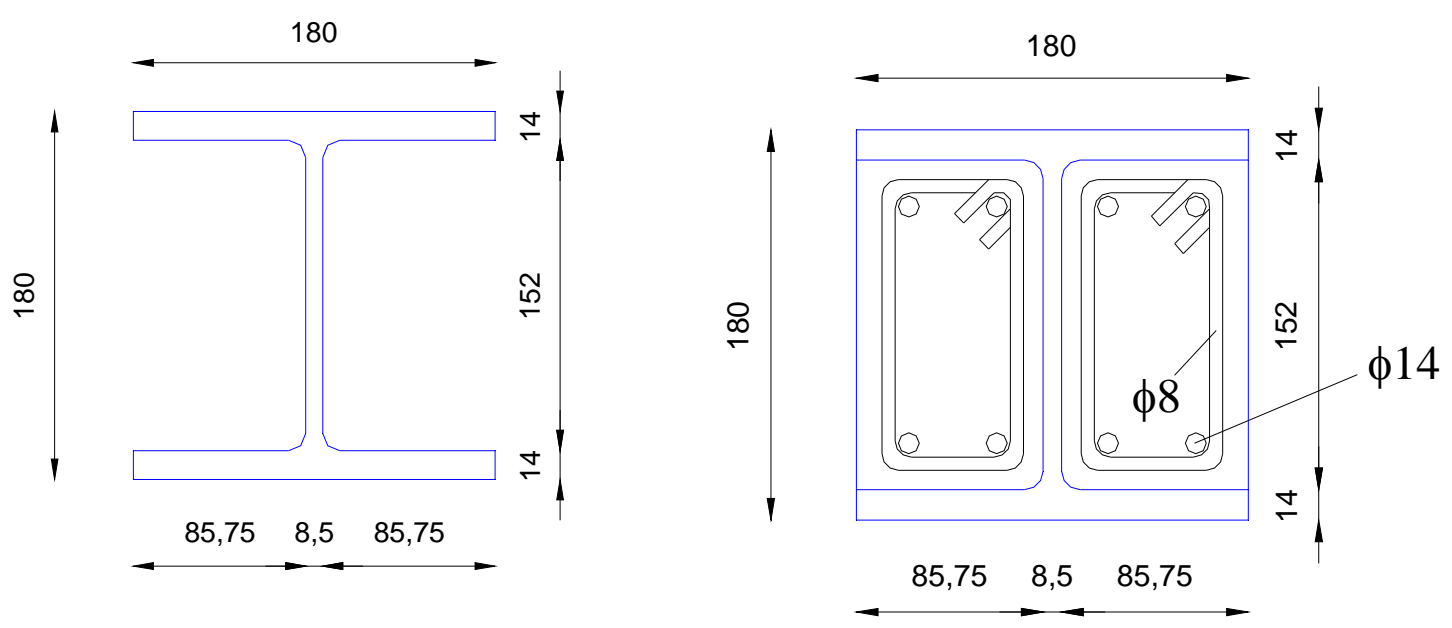

Figure 1. Section of the Specimen:

a) Steel Profile; b) Steel Profile with RC Reinforcement (Measures in mm) 
The experimental program includes specimens with and without steel reinforcement, oil along the interface before casting, monotonic and cyclic loading histories in compression and tension. Application of compressive, tensile and cyclic loads was aimed at investigating the seismic performance of the system also when, under cyclic action, load reversal can occur.

In Table $1 \mathrm{a}$ list of specimens with the following characteristics is reported: the type of load, the presence of steel reinforcement (Figure 1b) and oil along the interfaces, the mean compressive strength of concrete, $R_{\mathrm{cm}}$, evaluated on three cubes (side $150 \mathrm{~mm}$ ) for each casting. The profiles were made of steel type S275 (yielding strength $275 \mathrm{MPa}$ ) and the internal rebars were type Fe430 (yielding strength $430 \mathrm{MPa}$ ); in these tests the mechanical characteristics of steel were not experimentally evaluated since stresses were very low and far from yielding.

Each specimen was designed and constructed with the concrete part staggered from the steel one longitudinally by $50 \mathrm{~mm}$ at both ends (Figure 2a) in order to allow stress transfer between the two materials. Tests were carried out by placing the specimens in an electro-mechanical universal testing machine with a capacity of $300 \mathrm{kN}$ and anchoring the profile to a stiff steel plate at the base (Figure 3a). Using another stiff steel plate the compressive load was applied directly on the concrete; the tensile load was applied by gripping steel re-bars embedded in concrete, even in the presence of internal steel reinforcement (Figures $2 \mathrm{~b}$ and $3 \mathrm{~b}$ ).

Table 1. Data of Specimens for Bond Tests

\begin{tabular}{|c|c|c|c|c|c|}
\hline Specimen & Stress & Load & Internal steel & Oil & $\mathrm{R}_{\mathrm{cm}}[\mathrm{MPa}]$ \\
\hline C1 & Compression & Monotonic & - & - & 22 \\
\hline C2 & Compression & Monotonic & - & - & 22 \\
\hline C3 & Compression & Monotonic & - & - & 35 \\
\hline C4 & Compression & Monotonic & - & - & 35 \\
\hline C5 & Compression (on steel) & Monotonic & - & - & 35 \\
\hline Ca1 & Compression & Monotonic & Yes & - & 22 \\
\hline Co1 & Compression & Monotonic & - & Yes & 22 \\
\hline T1 & Tension & Monotonic & - & - & 22 \\
\hline T2 & Tension & Monotonic & - & - & 22 \\
\hline Ta1 & Tension & Monotonic & Yes & - & 22 \\
\hline To1 & Tension & Monotonic & - & Yes & 22 \\
\hline CYC1 & Compression-Tension & Cyclic & - & - & 35 \\
\hline CYCa1 & Tension-Compression & Cyclic & Yes & - & 35 \\
\hline CYCo1 & Tension-Compression & Cyclic & - & Yes & 35 \\
\hline
\end{tabular}

When the load is applied to the specimen (either in compression by the steel plate or in tension by the steel re-bars), the concrete blocks move with respect to the steel profile in which they are embedded; this activates the load transfer mechanism from concrete to steel with development of bond stress at the interfaces. For tests in compression in one case (specimen C5) the load was applied directly on the steel profile by turning the specimen over.

In all cases the stress transfer from the concrete blocks to the steel profile was measured and analysed. Thirteen strain gauges were glued on the steel profile along the interfaces before casting and on the outer surface of the flanges to measure strain distributions (Figures 4 - 5). Four displacement transducers were applied: two were placed vertically to measure the slip between the concrete and steel; the other two were positioned horizontally on two opposite sides to check the effects of accidental load eccentricity (Figure 3a). In Figures $4 \mathrm{a}$ and $\mathrm{b}$ specimens before casting with and without oil at the interfaces are depicted; in Figures $4 \mathrm{c}$ and $4 \mathrm{~d}$ the specimens arranged for the tensile tests with and without internal reinforcement are reported. 

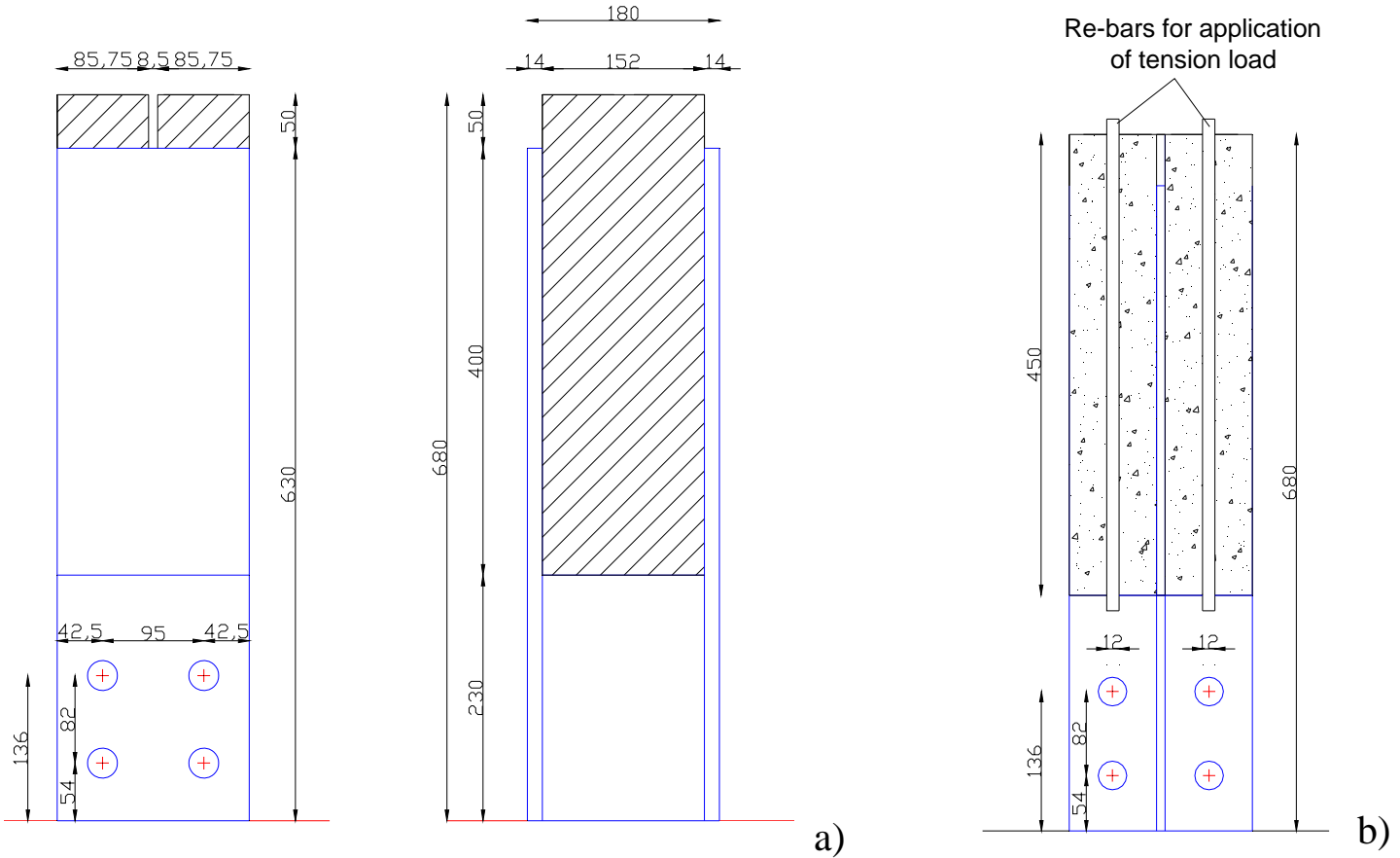

Figure 2. Specimen Geometry: a) Element in Compression; b) Element in Tension

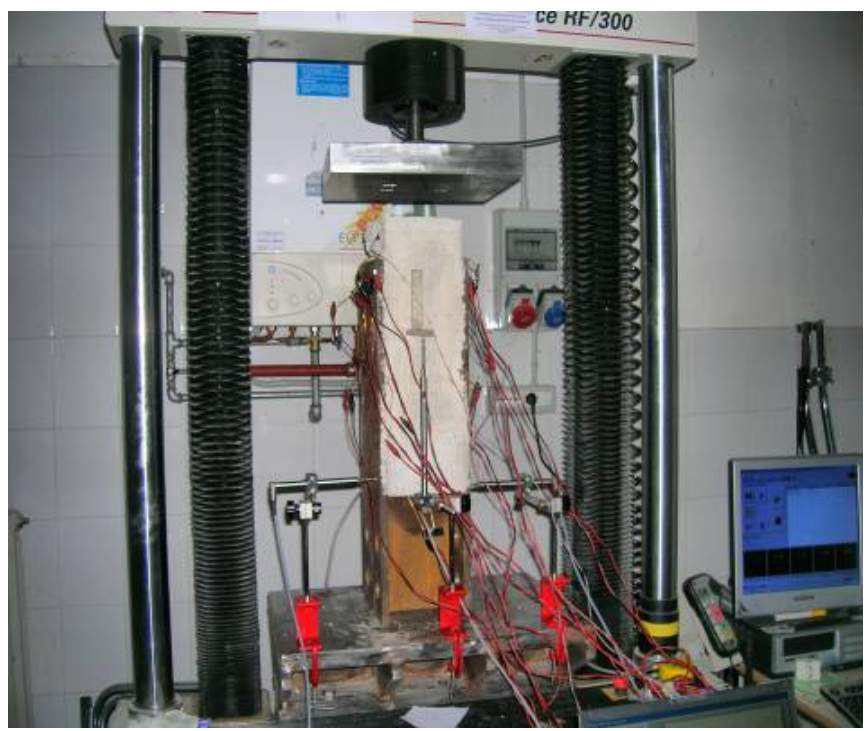

(a)

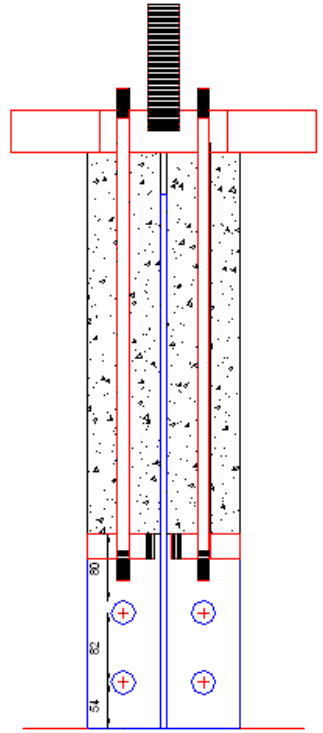

(b)

Figure 3. Set-up for Bond Tests on Composite Elements: a) Plate at the Base and Transducers; b) Plate at the Top and Rebars for Tensile Tests 


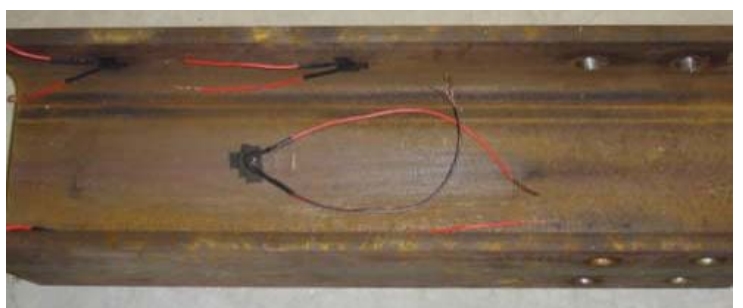

a)
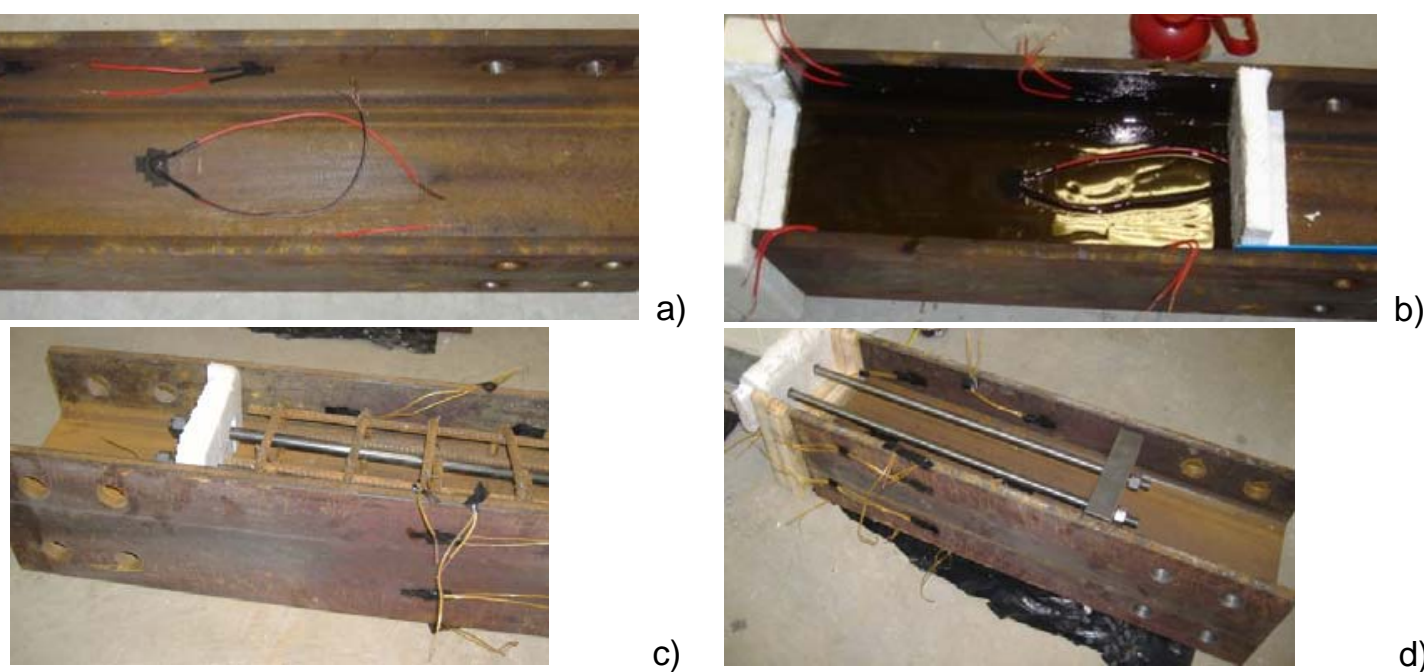

b)

c)

d)

Figure 4. a) Specimen for Compression Test; b) Specimen with Oil for Compression Test; c) Specimen with Internal Rebars and Reinforcement for Tensile Tests;

d) Specimen with Rebars for Tensile Tests
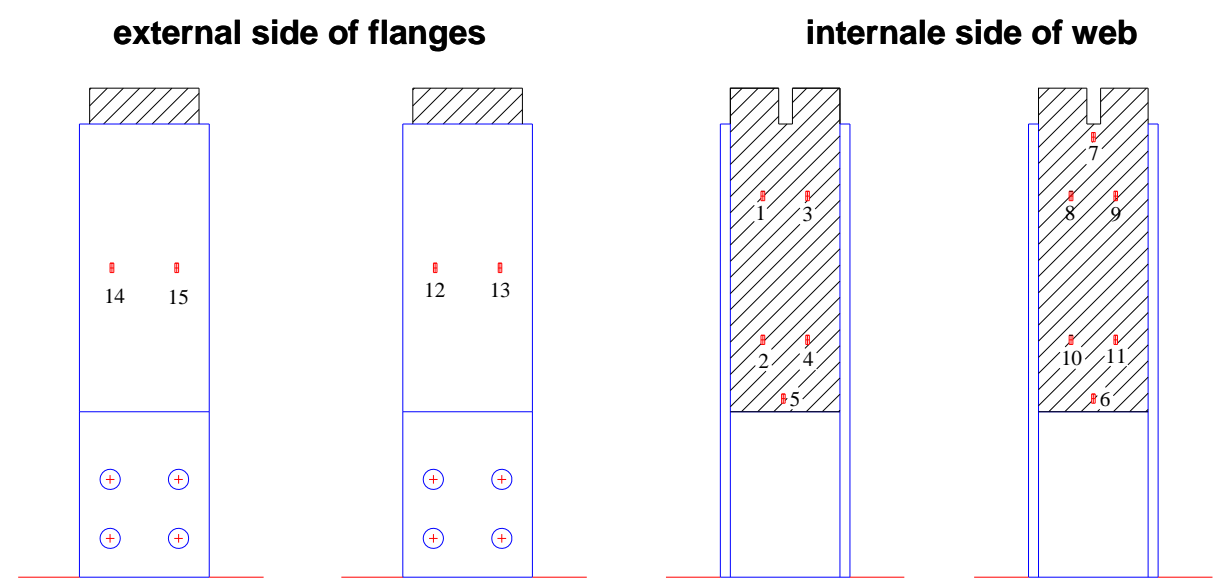

Figure 5. Position and Number of Strain Gauges

\section{EXPERIMENTAL RESULTS}

\subsection{Compression Tests}

The experimental load is plotted against slip curves obtained by monotonic tests in compression in Figures 6a-b; the slip is obtained as the mean value of the measures of the two vertical transducers. The elements marked C1 to C4 are characterized by two different castings of concrete with different compressive strengths (22 MPa for casting 1, 35 MPa for casting 2); element C5 (casting 2) was tested by applying the compressive load directly on the steel profile.

The bond-slip relations of specimens C1 and C2 (casting 1, Figure 6a) have a three-branch shape; the beginning of the curves shows a stiff behaviour without slip up to a peak bond strength, then there is a steep descending branch and finally a stable, practically horizontal, branch as far as great slips with a residual strength that is about $40 \%$ of peak stress. 

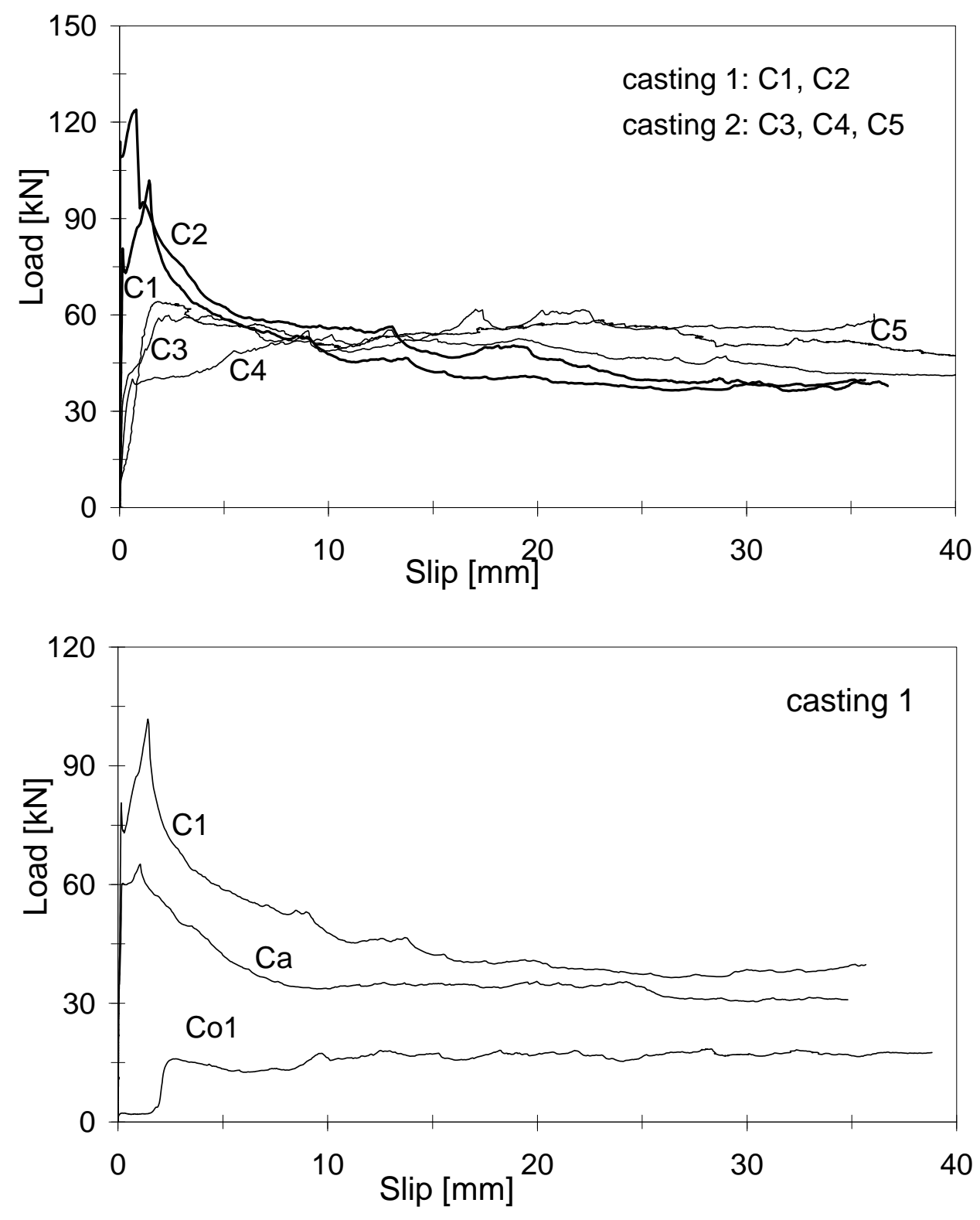

a)

b)

Figure 6. Load-slip Relationship for Specimens in Compression:

a) Standard Specimens; b) Specimens with Oil and Internal Reinforcement

The experimental curves of specimens C3 and C4 (casting 2, Figure 6a) have a different shape from the previous ones: small slips occur from the beginning, there is no peak of stress, the maximum load is attained in the horizontal branch (mean value $=50 \mathrm{kN}$ ) and is greater than the residual strength of specimens C1 and C2 (mean value $=30 \mathrm{kN}$ ) of about $24 \%$. For specimen C5, tested (same casting 2) by applying the compressive load on the steel profile, the result is similar with slips from the beginning and the same value of residual strength $(50 \mathrm{kN})$.

The different shapes of the $\tau$-s curves at the beginning up to the descending branch, on varying the concrete casting, point to the sensitivity of the phenomenon to concrete quality, environmental conditions (humidity and temperature) during hardening (the second casting was done in summer) and shrinkage effect; furthermore in the first mixer a suitable additive to reduce shrinkage was used. The residual strength after peak depends on average upon concrete strength: the greater concrete strength of the second casting causes an enhancement of the residual strength. 
In Figure $6 \mathrm{~b}$ the reference specimen $\mathrm{C} 1$ is compared with specimens $\mathrm{Co} 1$ and $\mathrm{Ca} 1$, belonging to the same casting, with oil at the interface and internal steel reinforcement, respectively. The surface treatment with oil eliminates the initial effect of adhesion, the horizontal branch is reached without a peak and the maximum load is about $25 \%$ of that of the specimen without oil. A negative effect of internal steel reinforcement appears with a load reduction both at the peak and horizontal branch, the residual load being about 15\% lower than standard specimens. This last result may well be due to a lower concrete quality since it is more difficult to vibrate concrete in the presence of steel rebars to have homogeneity; concrete thickness $(20-30 \mathrm{~mm})$ between the steel rebars and the profile surface, that govern the interface bond, could be particularly influenced by inefficient vibration. The detrimental effects of internal reinforcement on bond performance could definitely be reduced in real composite columns characterized by greater dimensions of the concrete section which, due to the thicker cover of the steel rebars, allow better concrete quality particularly along the steel profile interfaces.

In conclusion, the shape of the $\tau$-s curve is sensitive to the quality of concrete depending on several factors (casting and hardening conditions, shrinkage, internal reinforcement), and the effective bond shear strength can be identified as that corresponding to the horizontal branch after the peak. This value is less than proportional to concrete strength (when compressive strength increases by $50 \%$, bond strength increases by $24 \%$ ), but depends heavily on surface roughness, since it falls below $50 \%$ when steel surfaces are impregnated with oil.

\subsection{Tensile Tests}

The experimental results of bond tests on specimens loaded in tension are presented in Figure 7a; the bond-slip curves of these specimens are compared with those tested in compression (C1, C2) and belonging to the same casting (casting 1). The experimental relations show that adhesion and friction phenomena at the beginning are much lower than in compression tests and slips are considerable also for low loads. The shape of the curve is similar to that in compression with a peak and a sharp descending branch, after which the almost horizontal line gives about the same residual strength ( $40 \%$ of peak) as that recorded in compression.

The different behaviour in compression and tension at the beginning of the test is related essentially to the development of greater slip when the tensile load is applied. This result is probably due to the beneficial lateral expansion of concrete in the compression test that improves the friction contribution. After the friction effect wears off, bond behaviour becomes similar for both tensile and compressive loading conditions.

In Figure 7b specimen $\mathrm{T} 1$ is compared with the other two of the same casting, but treated with oil at the interface and with internal steel reinforcement. Reduction in surface roughness due to oil has the same effect observed in the compression test: the peak disappears and the residual strength reduces to $25 \%$ of the reference specimen without oil. Analogously the internal reinforcement, as in the compression test, reduces bond efficiency, eliminating the peak and decreasing the residual strength to $70 \%$ of the reference specimens (T1). Effects of oil and internal reinforcement are related to the same phenomena already described for the compression tests.

Finally, the bond tests carried out by applying tensile loads to the concrete blocks confirm the results obtained in compression tests, highlighting appreciable effects of friction at the steel-concrete interfaces that are drastically reduced by oil or concrete quality. 


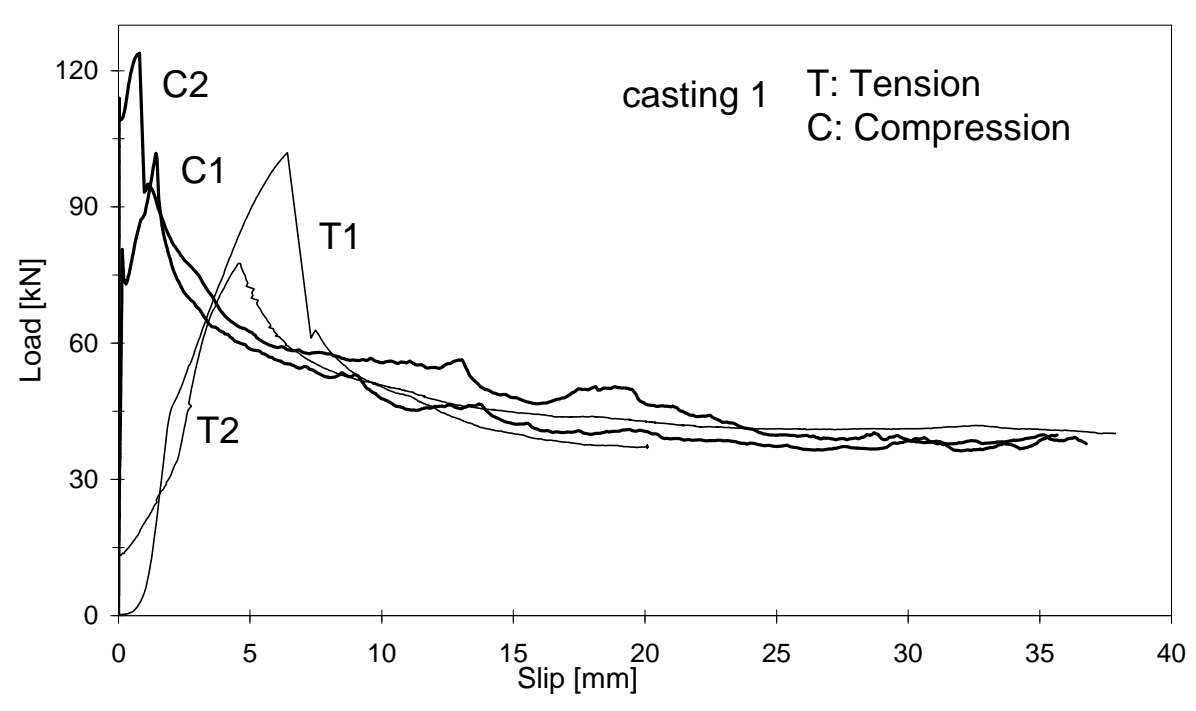

a)

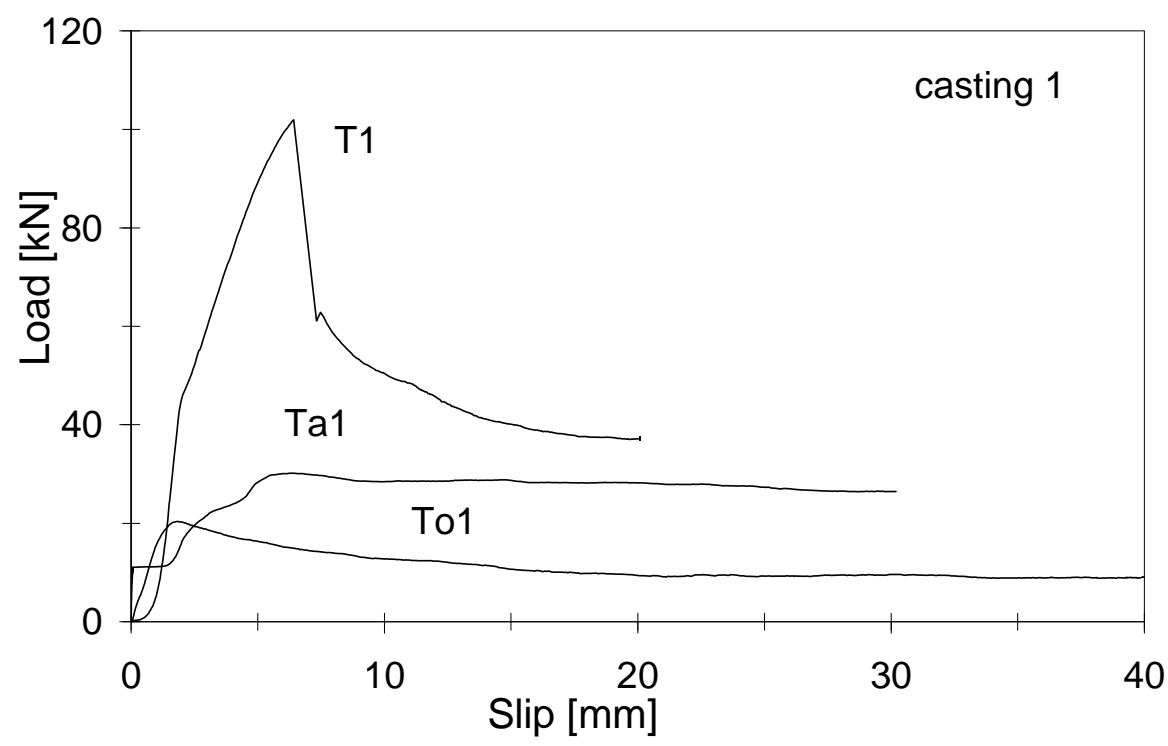

b)

Figure 7. Load-slip Relation for Specimens Tested in Tension: a) Standard Specimens Tested in Tension and Compression; b) Specimens with Internal Reinforcement and Oil

\subsection{Cyclic Tests}

As regards the three cyclic tests, aimed to analyse the structural response under seismic actions, the first (CYC1, casting 2) was carried out by first applying a monotonic compression load history, five cycles were then done between $+20 \mathrm{kN}$ and $-20 \mathrm{kN}$, a monotonic compression load was applied up to a slip of $17 \mathrm{~mm}$ and finally the load was reversed to achieve a zero slip (Figure 8a).

Interestingly, during the five cycles at a load equal to about $40 \%$ of the monotonic strength (specimens C3 and C4 belonging to the same casting) when the load becomes zero, the slip is not recovered and higher slip values are required to regain the same load. An evident phenomenon of pinching occurs and the load is regained only when slip becomes as higher as concrete is able to contrast again the steel profile along the interfaces where friction is not yet overcame. Pinching is typical of bond mechanisms under cyclic loads that is well-known for the bond-slip behaviour of steel bars in reinforced concrete elements or more in general in all phenomena where strength is based on a shear stress transfer between separate components (i.e. at the interfaces of shear cracks in concrete elements). 


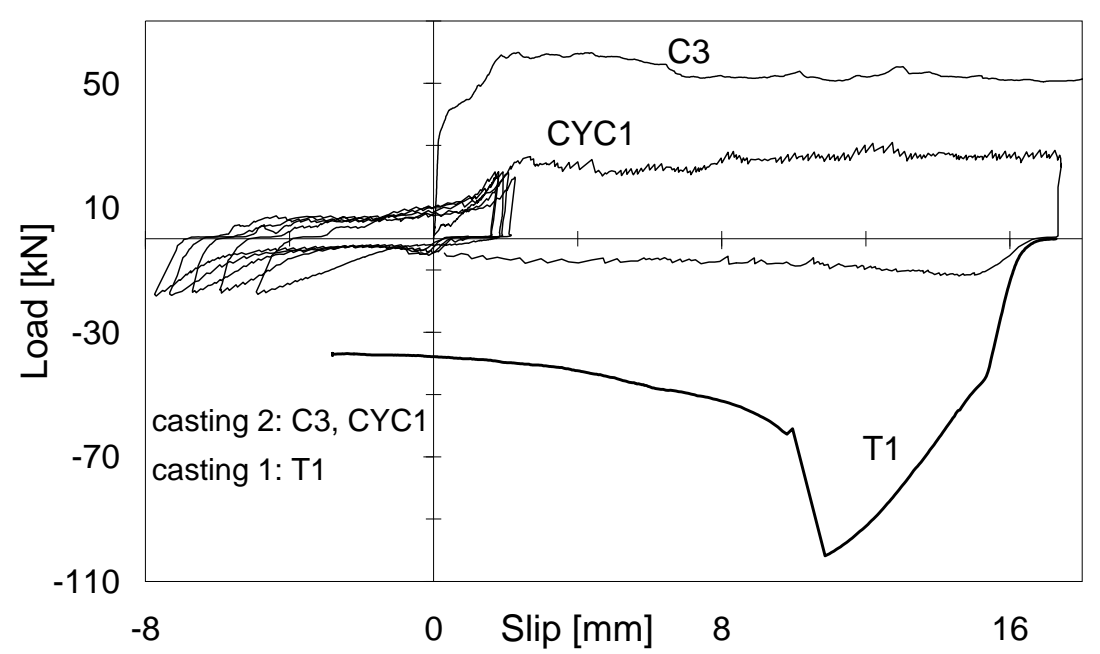

a)

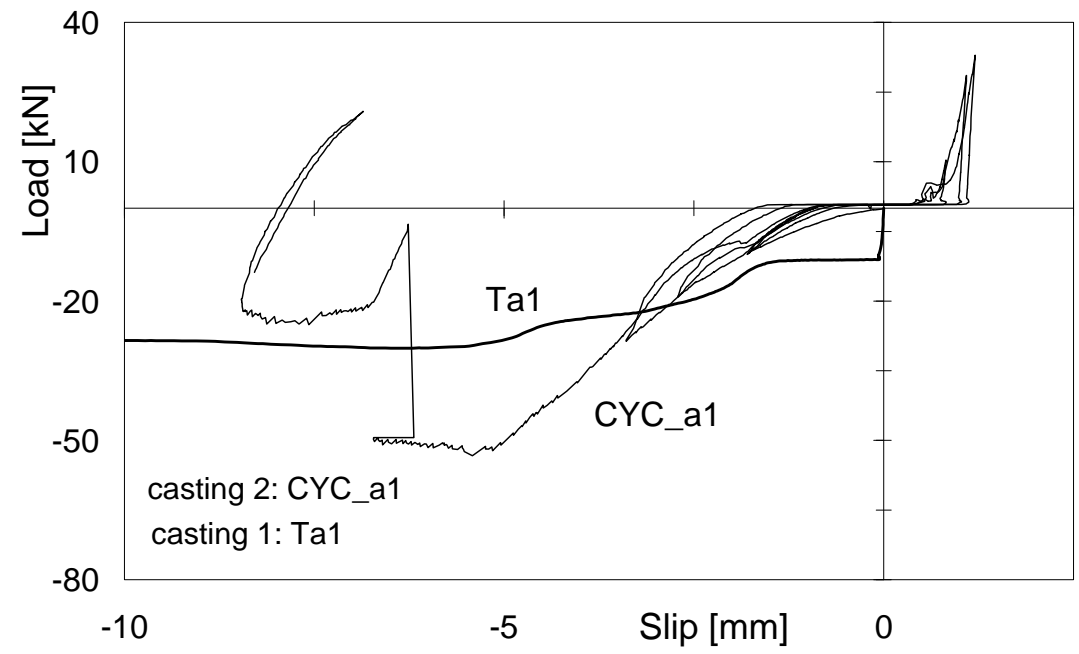

b)

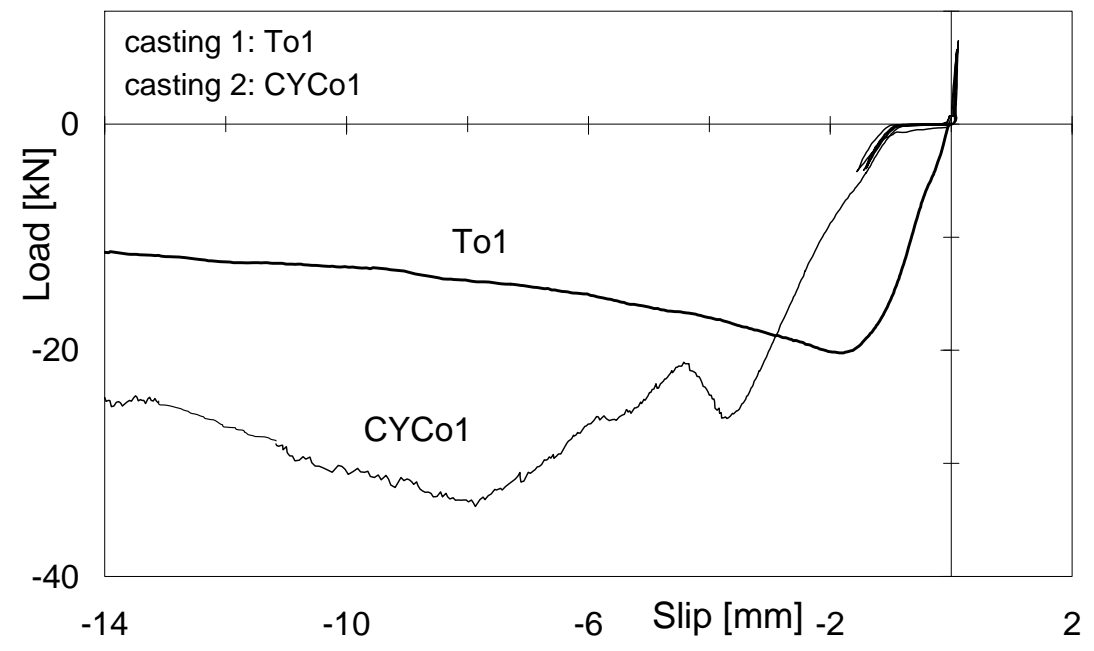

c)

Figure 8. Load-slip Relationship for Cyclic Tests: a) Test Started in Compression;

b) Test Started in Tension; c) Test on Specimen with Oil 
Comparison of the cyclic curves with the monotonic one of a similar specimen belonging to the same casting (C3) shows that residual strength after 5 cycles is about half the monotonic. In the last branch in tension the cyclic curve shows a higher strength reduction than the monotonic, that still refers to a specimen T1 (casting 1) with a concrete strength (22 MPa) lower than that (35 MPa) used for the cyclic tests (casting 2).

In Figure 8b the experimental load vs. slip curve is depicted for a cyclic test on specimen CYCa1 (casting 2) with internal steel reinforcement and loaded first in tension. In this case five cycles were imposed between $+30 \mathrm{kN}$ and $-30 \mathrm{kN}$. The same pinching effect is evidenced and the residual strength reduces by about $18 \%$ against the same specimen (Ta1) loaded monotonically, but belonging to casting 1 with a lower strength (22 MPa).

Finally, Figure 8c shows the result of a cyclic test on specimen CYCo1 treated with oil at the interface. This test was started by loading the specimen first in tension, and then five cycles between $+5 \mathrm{kN}$ and $-5 \mathrm{kN}$ were applied; the test was completed by applying monotonically the load until a residual constant strength was attained. Comparison of the cyclic with the monotonic curve (specimen To1, made of lower strength concrete $22 \mathrm{MPa}$ ) shows there is no reduction in strength due to cyclic loads since the influence of friction, that strongly degrades under cyclic loads, is already reduced by oil.

\section{COMPARISON OF EXPERIMENTAL RESULTS AND CODE PROVISIONS}

\subsection{Code Provisions}

The capacity of composite elements to avoid slip between concrete and steel is related to suitable bond stresses at the interface or to mechanical connections. The Italian code (NTC, 2008) gives the following bond strengths to design composite columns, according to the type of element:

- fully encased: $0.30 \mathrm{MPa}$

- circular concrete-filled: $0.55 \mathrm{MPa}$

- rectangular concrete-filled: $0.40 \mathrm{MPa}$

- for the flanges of partially encased: $0.20 \mathrm{MPa}$

- for the web of partially encased: $0.00 \mathrm{MPa}$

If these limits are exceeded, the entire load has to be transferred by connectors. The same limits are also recommended by Eurocode 4 [5], and similar values were provided in the previous edition of Eurocode 4 and in the Italian guidelines devoted to composite elements (CNR 10016 [7]); in these instructions it was clearly stated that in the joints between elements the transfer length must be no greater than twice the smallest dimension of the cross section. The American code (AISC [6]) gives similar values for concrete-filled columns (0.40 MPa), supplies suggestions about the transfer length at joints, and recommends to neglect bonds for partially encased columns.

The Italian code (NTC [8]) states that for structures under seismic action the transfer of shear stresses by bond mechanism can be not sufficient so that mechanical connectors have to be introduced to guarantee the composite action. In the European code for seismic constructions (Eurocode 8 [13]) the transfer of stresses is not dealt with, but constructive details and geometrical limits have to be applied in the design to assume active collaboration between materials and to develop the required ductility. In columns partially encased with double $\mathrm{T}$ profiles, the concrete between flanges can be connected to the web with steel stirrups or rebars in order to form a clear transfer mechanism between the concrete and the steel web. 


\subsection{Experimental Shear Stresses}

In the hypothesis that bond interaction is effective along the entire interface, the mean values of experimental shear stresses are evaluated by dividing the applied load (tensile or compressive) by the entire interface area of the steel profile $\left(\tau=N / A_{p}\right.$ with $\left.A_{p}=29.910^{4} \mathrm{~mm}^{2}\right)$. In Figure 9 the shear stresses are plotted versus slips for all the monotonic tests. Clearly, bond strength (the value indicated by the horizontal branch) is always lower than the limit of $0.2 \mathrm{MPa}$ laid down by EC4 for flanges but higher than zero suggested for the web.

In order to compare the experimental results with the code limits, it seems more appropriate to take into account only the flange interfaces since most codes neglect the web contribution; hence shear stress is re-calculated by dividing the applied load by the interface area of flanges $\left(\tau=\mathrm{N} / \mathrm{A}_{\mathrm{fl}}\right.$ with $A_{\mathrm{fl}}=16.210^{4} \mathrm{~mm}^{2}$ ). The bonded area of the flanges alone is about half the entire bonded area, such that the bond stresses are about double those previously evaluated, as shown in Figure 9. In Figure 10 the new mean shear stresses are plotted versus slips. All compressive tests, except the specimen treated with oil, show a residual strength greater than $0.2 \mathrm{MPa}$; for tensile tests the specimens with oil and internal reinforcement give values below this limit.

The strain gauges glued on each specimen allowed local shear stresses to be calculated. If the measured strains are multiplied by the elastic modulus of steel the stresses in the profile can be determined neglecting the transversal stresses induced by the transversal deformation of the embedded concrete blocks; this assumption was confirmed by the negligible values of transversal strains in the steel profiles measured by two transducers positioned orthogonally to the specimen axis (Figure $3 \mathrm{a}$ ). The difference between stresses in steel at two consecutive points gives the load transferred in this length which, divided by the interface area, gives the shear stress. Shear stresses can be calculated on the flanges or on the web where the strain gauges are glued; the following formula is used to determine shear stress along the flanges:

$$
\tau(x)=t_{f} \cdot B \cdot E_{s} \cdot \frac{\Delta \varepsilon_{i}}{\left(B-t_{w}\right) \cdot \Delta x_{i}}
$$

$\mathrm{t}_{\mathrm{f}}$ being the thickness and $\mathrm{B}$ the width of the flange, $\mathrm{t}_{\mathrm{w}}$ the thickness of the web, and $\Delta \mathrm{x}_{\mathrm{i}}$ the distance between two consecutive strain gauges.

In Figure 11a showing an example (specimen C1) of shear stress distribution, the flanges demonstrate a greater transfer between points placed at $100 \mathrm{~mm}$ and $200 \mathrm{~mm}$ from the loaded end (the end of the steel profile). Furthermore, normal stresses increase going away from the loaded end $(\mathrm{x}=0 \mathrm{~mm})$. In Figure 11b the comparison between local bond stresses $\left(\tau_{1}\right.$ and $\tau_{2}$, respectively, at position $100 \mathrm{~mm}$ and $200 \mathrm{~mm}$ from the loaded end) and mean bond stress ( $\tau=N / A_{p}$, with $A_{p}$ of flanges) shows good agreement.

Evaluation of local stresses in steel is useful to accurately determine the distribution of load between the profile components and to define the length necessary to transfer the entire load. The steel stresses in the web and the flanges at $300 \mathrm{~mm}$ from the loaded end are multiplied by the respective area to calculate the force sustained by each sub-component. In Figure 12 the sum of both contributions is compared with the entire applied load: good agreement is shown until the maximum load is reached. This proves that the flanges play the main role supporting almost the entire force, even if the bonded area of web and flange is about the same. This last observation seems to re-confirm the recommendation of Italian and European codes to neglect the bond strength of the web. It is also worth noting that the load transfer is exhausted in the length between the 
measuring points (200 mm and $300 \mathrm{~mm}$ ), since it proved complete at $300 \mathrm{~mm}$ from the loaded end. After the peak the contributions of the sub-components decline, while the applied load remains quite constant. This means that the bond strength was exceeded in the first part of the bonded length and the transfer of shear stresses moved to the remaining undamaged interface (not instrumented) that is still sufficient to sustain a slightly lower than maximum load.

In Figures 13a and 13b the stress-slip curves of Khalil [9] related to concrete-filled square hollow sections (side $h_{a}=150 \mathrm{~mm}$ and thickness $t=5 \mathrm{~mm}$ ) are plotted; the compressive strength of concrete was about $50 \mathrm{MPa}$. The specimens were realized with and without oil and are characterized by three different bond lengths (250, 450, and $600 \mathrm{~mm})$. The results of specimens without oil show that both peak and residual strengths exceed the Italian code threshold (NTC [8]) for concrete-filled rectangular sections (0.40 MPa) only for a bond length of $250 \mathrm{~mm}$; for greater bond lengths the mean experimental value is $0.30 \mathrm{MPa}$. In the presence of oiled surfaces, the strength declines considerably (about 50\%) for all the bonded lengths tested.

In Figures 14a and 14b the experimental results presented herein for partially encased elements are compared with those of Khalil [9], already introduced, and the others of Mouli and Khelafi [12] realized on concrete-filled rectangular sections (mean strength of $45 \mathrm{MPa}$ ) with a bond length of $450 \mathrm{~mm}$. For these tests both the results without (Figure 14a) and with oil (Figure 14b) are analysed. It can be observed that the code limits are not safe for concrete-filled columns and safe, albeit with a low margin, for the partially encased ones. For specimens treated with oil, residual strength is strongly reduced in both types of columns once again indicating the importance of roughness upon the bond stress transfer mechanism.

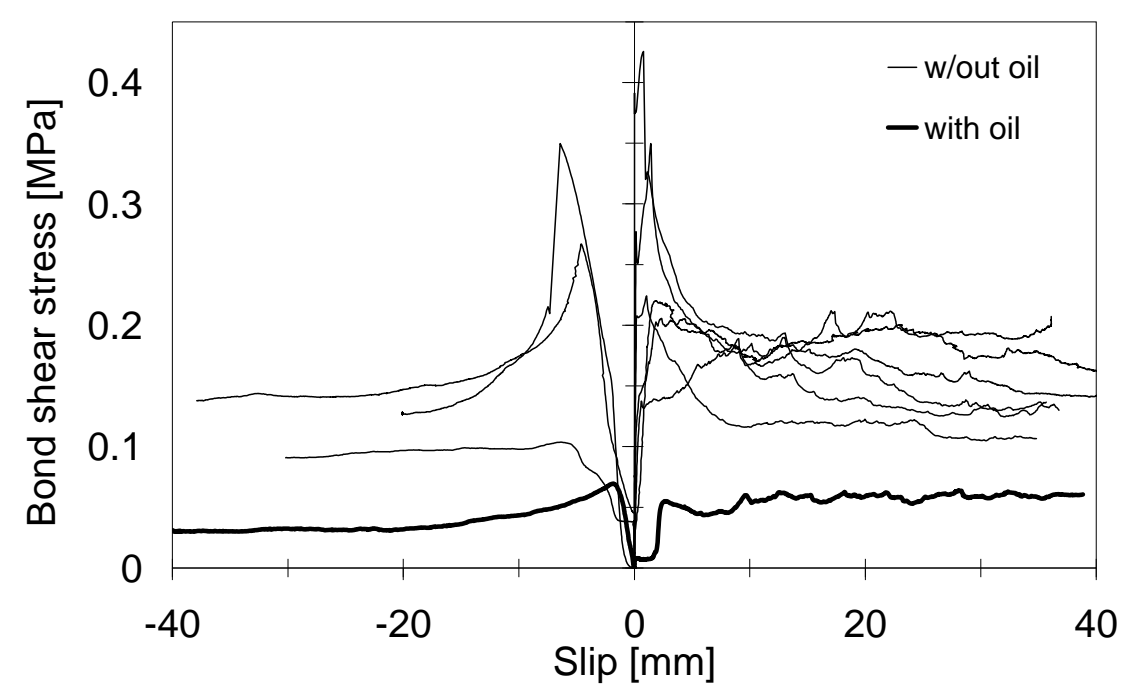

Figure 9. Shear Stress-slip Relationship for All Monotonic Tests 


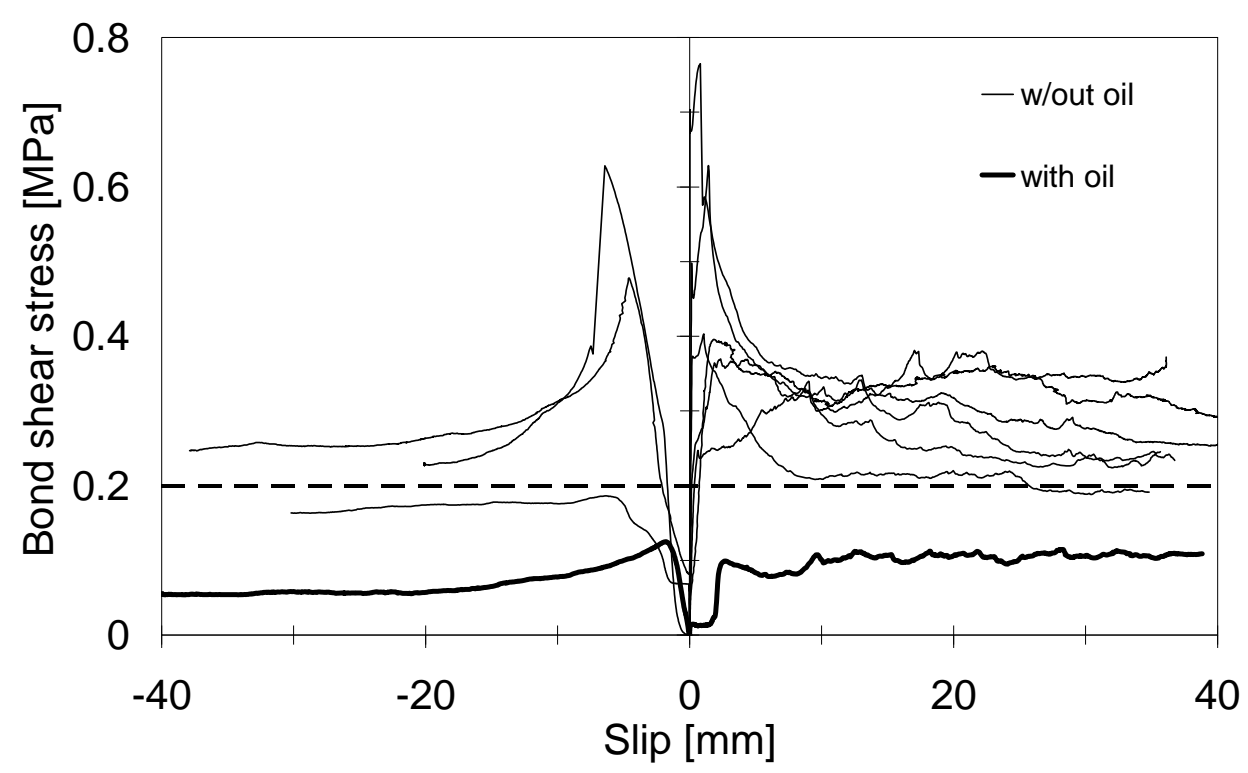

Figure 10. Bond Stress-slip Relationship of All Monotonic Tests assuming only the Flanges Adherent

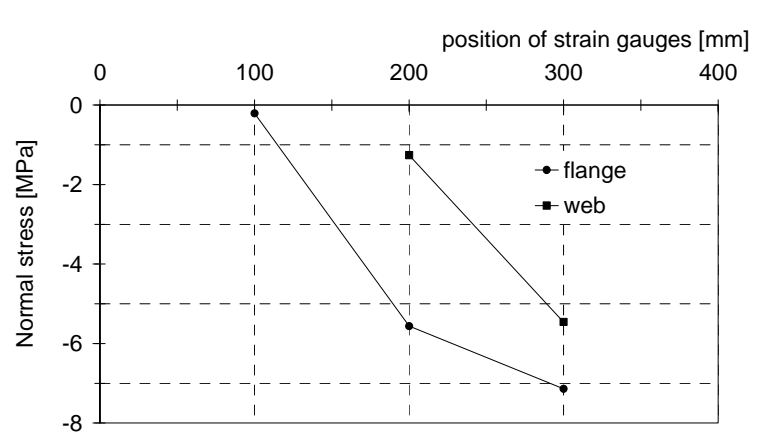

a)

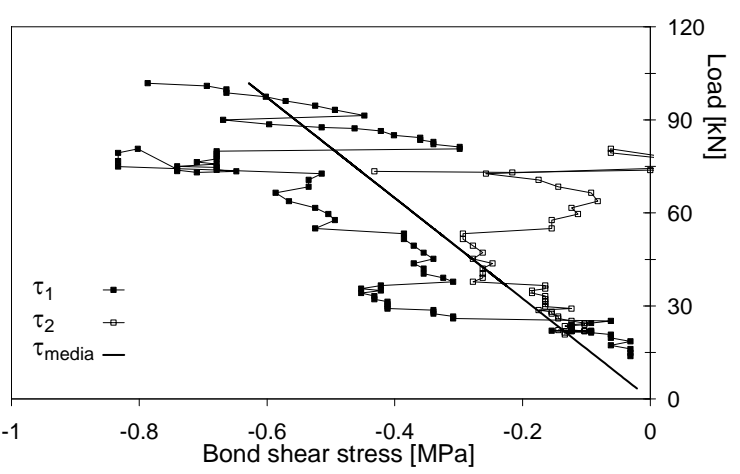

b)

Figure 11. a) Variation of the Bond Stresses along the Flange and the Web of Specimen C1; b) Comparison of Local and Mean Values of Bond Strength for Specimen C1 


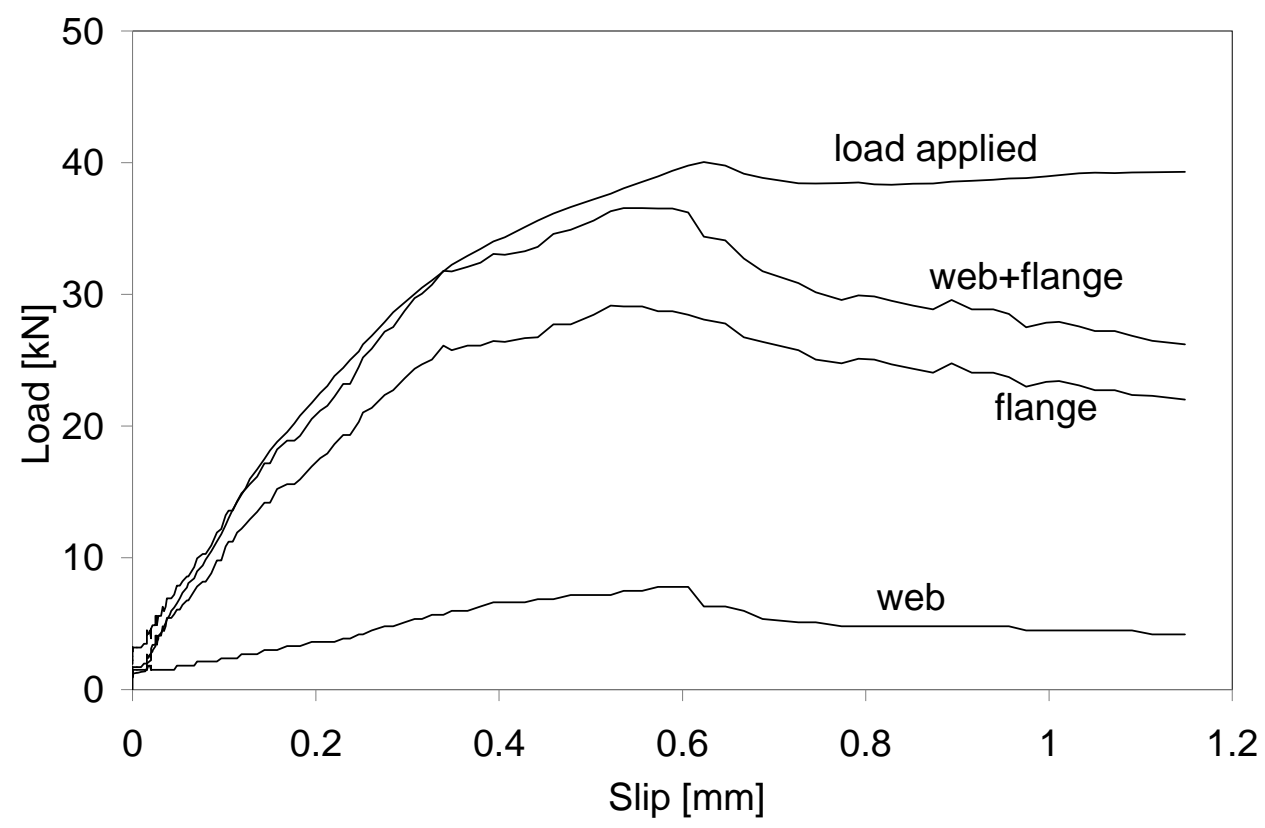

Figure 12. Contributions of the components 

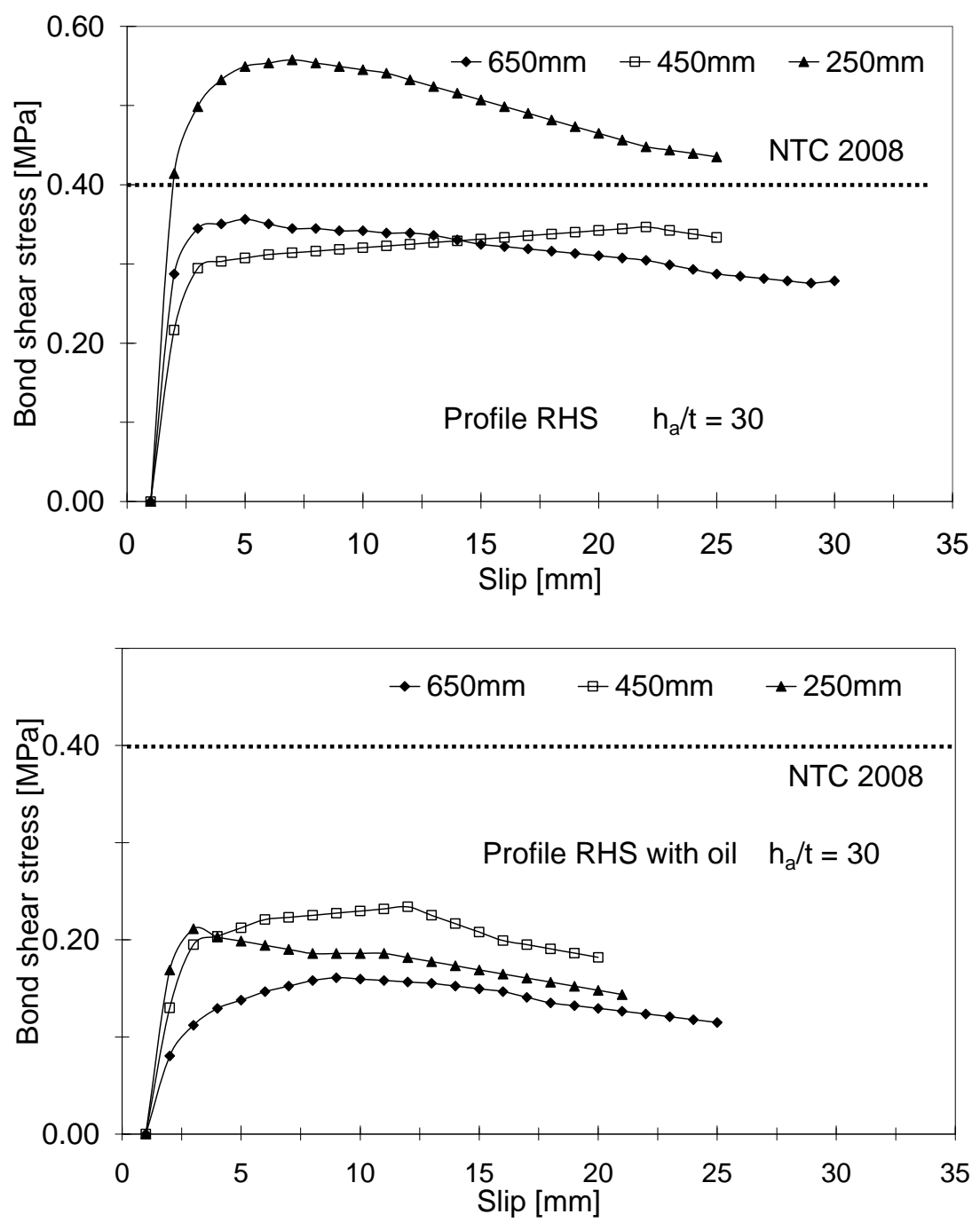

a)

b)

Figure 13. Bond Stress-slip Relationships of Tests by Khalil (1993): a) Concrete-filled Square Sections; b) Concrete-filled Square Sections with Oil at the Interface 


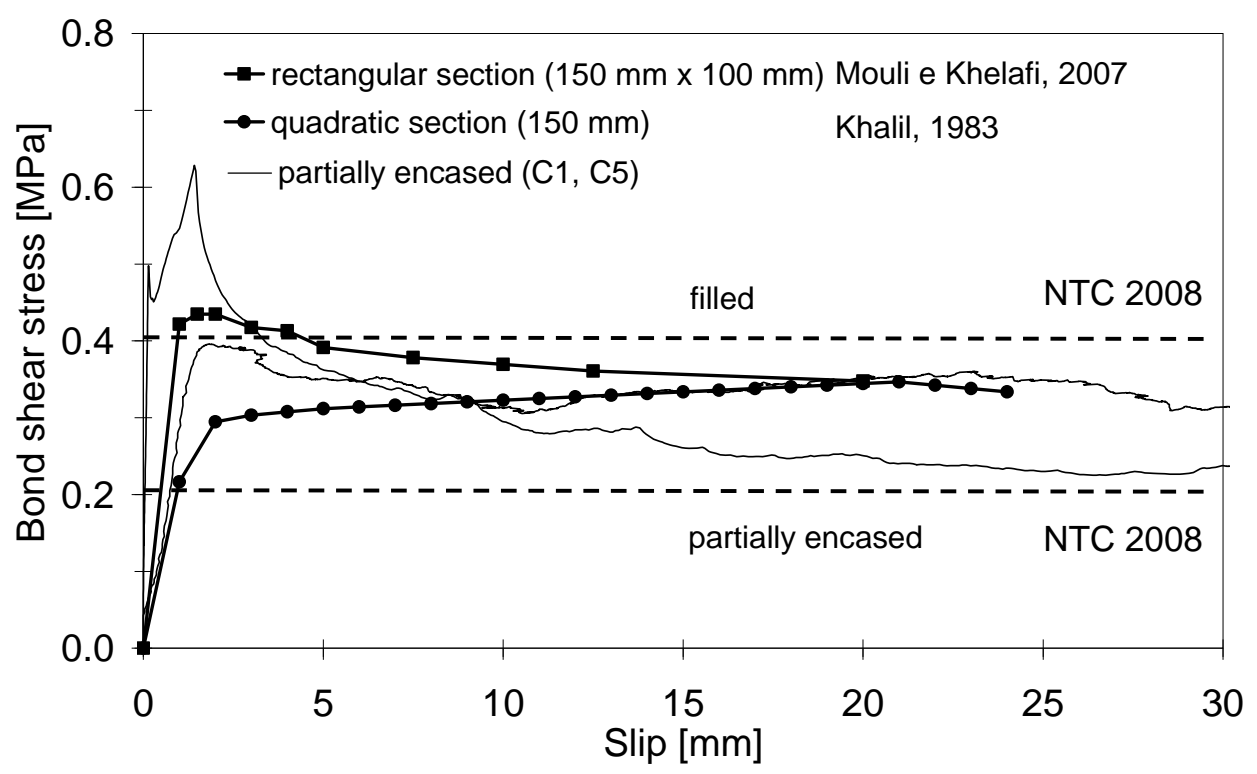

a)

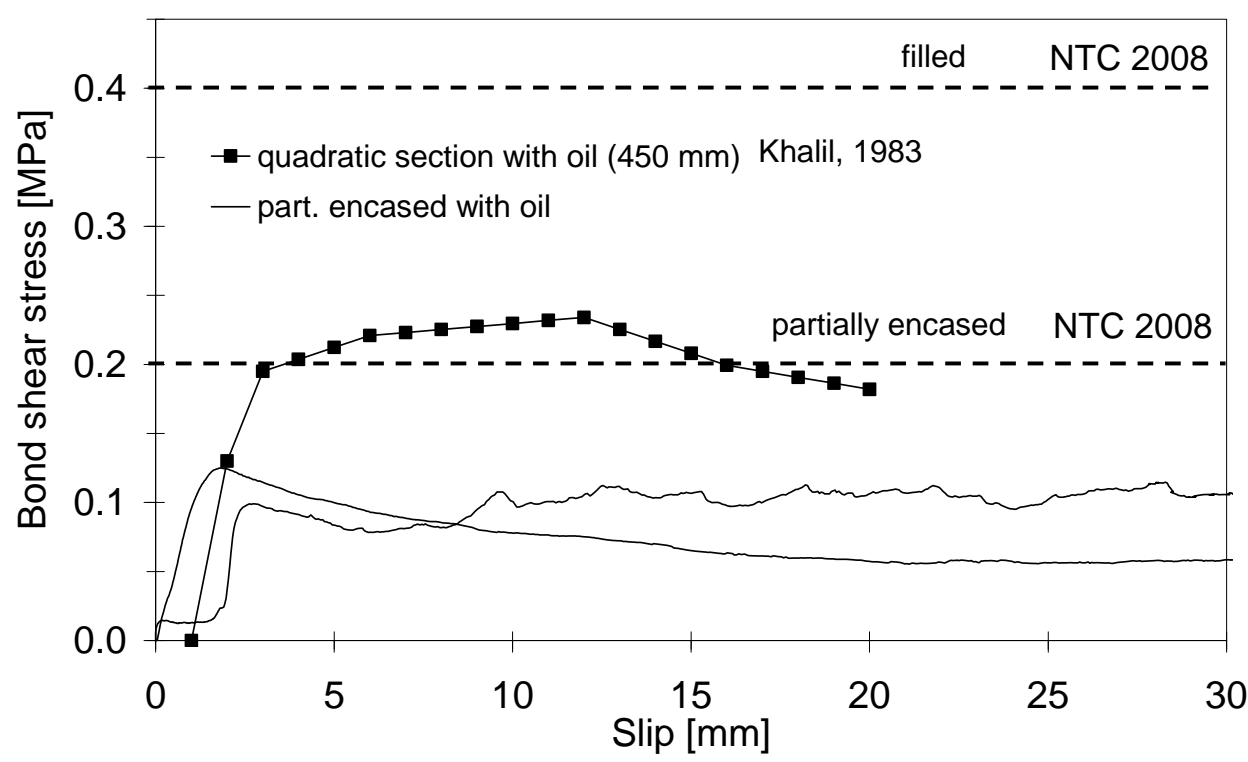

b)

Figure 14. Comparison of the Experimental Results on Partially Filled Columns with those of Khalil [9] and Mouli and Khelafi [12]: a) Specimens without Oil; b) Specimens with Oil 


\section{CONCLUSIONS}

The bond tests carried out to study bond behaviour at the steel-concrete interface in partially encased composite columns provided much information that was hitherto lacking in the technical literature. The first part of the bond-slip relationship is strongly influenced by adhesion and friction, that can result in a very stiff initial branch up to a peak followed by a sharp descending branch and a last horizontal branch with a constant residual bond stress. In other cases, depending on the casting condition of concrete, the behaviour at the beginning is less stiff and the horizontal branch occurs without a peak being reached before. Evidently, bond strength is defined by the horizontal line that allows large slip values to develop.

Application of compressive or tensile loads does not change the residual value of bond strength, that is also invariable if the load is applied on concrete or steel, even though this aspect was analyzed in only one test. The compressive strength of concrete influences the bond strength according to a lower than proportional dependence. Hence concrete strength does not appear a relevant parameter, as already assumed in the codes that set a limit value of bond strength depending only on column type. The specimens with oil at the interfaces showed a reduction in bond strength to less than $50 \%$ that of the reference ones, confirming the importance of friction related to the roughness of the contact surfaces.

A reduction in bond strength of about $10-20 \%$ is also due to the presence of internal steel reinforcement made of longitudinal steel rebars and stirrups, that influence the quality of concrete due to practical difficulties in vibrating the concrete homogeneously in the reduced thickness between the rebars and the surface of the steel profile. Application of tensile load highlights a negligible effect on bond strength and a lower friction effect in the ascending branch due to the absence of transversal dilatation of concrete when tension is applied.

Analysis of the local measures on the web and flanges confirms the higher collaboration of flanges, as suggested by the Italian and European codes. Measurements of the transferred stresses also suggest the transfer length is between $200-300 \mathrm{~mm}$, i.e. 3 times the width of the steel flanges.

The comparison of the results obtained in this experimental program with those of other authors on concrete-filled columns points out that friction is more important in partially encased columns, since the reduction in roughness by treating surfaces with oil causes a larger decrease in bond strength with respect to concrete-filled elements. Finally, the few tests executed according to cyclic load histories show a strong degradation of stiffness and strength in the bond-slip relationship due to the reduction of the fundamental effect of friction.

As regards design provisions, the experimental values of bond strength are always higher than the limit established by Italian and European codes, if the web contribution is neglected and the stress transfer is attributed only to the flanges, as codes suggest. However, since the experimental results show that the limits of the codes do not guarantee a safety factor, the approach of AISC which neglects bond strength in partially encased columns seems sound. Overall, the recommended limits in European and Italian codes need to be reviewed with a view to a reduction, and details about surface conditions may well have to be introduced. Furthermore, in seismic areas the bond contribution has surely to be neglected and suitable connectors have to be applied to guarantee strength and stiffness under cyclic action. 


\section{ACKNOWLEDGEMENTS}

The experimental tests presented in this paper were carried out by the research unit of the University of Sannio for the RELUIS project - task 5 financed by the Civil Protection Department in the period 2005-2008.

\section{REFERENCES}

[1] Cosenza, E. and Zandonini, R., "Composite Construction”, Handbook of Structural Engineering - W.F. Chen Ed., CRC. Boca Raton, Florida, 1997.

[2] Virdi, K.S. and Dowling, P.J., "Bond Strength in Concrete Filled Steel Tubes”, Proc. of the IABSE Periodica, 1980, pp. 125-130.

[3] Hamdam, H. and Hunaiti, Y., "Factors Affecting Bond Strength in Composite Columns", Proceedings of the $3^{\text {rd }}$ International Conference on Steel-Concrete Composite Structures, Fukuoka, Japan, 1991, pp. 213-218.

[4] Hunaiti, Y.M., “Aging Effect on Bond Strength in Composite Sections”, Journal of Materials in Civil Engineering, 1994, Vol. 6, No. 4, pp. 469-473.

[5] Eurocode 4, "Design of Composite Steel and Concrete Structures - Part 1.1: General Rules and Rules for Buildings”, European Committee for Standardization, 2004, Brussels, Belgium.

[6] American Institute of Steel Construction, "Specification for Structural Steel Buildings", ANSI/AISC, 2005, 360-05, Illinois, Chicago.

[7] CNR 10016, "Strutture Composte di acciaio e Calcestruzzo Istruzioni per l'impiego Nelle Costruzioni”, CNR Bollettino Ufficiale no. 194 - Norme tecniche, Parte IV, 1999, Roma.

[8] Min.LL.PP, DM 14 gennaio, “Norme Tecniche per le Costruzioni (NTC)”, Gazzetta Ufficiale della Repubblica Italiana, 2008, No. 29 (in Italian).

[9] Khalil, H.S., "Push-out Strength of Concrete-filled Steel Hollow Sections”, The Structural Engineer, 1993, Vol. 71, No. 13, pp. 230-233.

[10] Kilpatrick, A.E. and Rangan, B.V., "Influence of Interfacial Shear Transfer on behavior of Concrete-filled Steel Tubular Columns”, ACI Structural Journal, 1999, Vol. 96, S72, pp. 642-648.

[11] Johansson, M. and Gylltoft, K., "Mechanical Behavior of Circular Steel-Concrete Composite Stub Columns”, Journal of Structural Engineering, 2002, Vol. 128, No. 8, pp. 1073-1080.

[12] Mouli, M. and Khelafi, H., "Strength of Short Composite Rectangular Hollow Section Columns Filled with Lightweight Aggregate Concrete”, Engineering Structures, 2007, Vol. 29, No. 8, pp. 1791-1797.

[13] Eurocode 8, "Design of Structures for Earthquake Resistance - Part 1: General Rules, Seismic Actions and Rules for Buildings”, European Committee for Standardization, 2003, Brussels, Belgium. 